\title{
Thermodynamic Study on Fused Binary Alloys by Electromotive Force Measurement (Zn-Sb System)
}

\author{
Zensaku Kozuka, Jyoichiro Moriyama, and Isao Kushrma* \\ Dept. of Metallurgy, Faculty of Engineering, Kyoto University, Kyoto
}

In this paper, the result obtained for the thermodynamic properties of $\mathrm{Zn}-\mathrm{Sb}$ binary solution by $e . m . f$. measurement is reported. In respect to this system, Seltz et al. ${ }^{1}$. presented that its solution has unusual thermodynamic property.

The cells of the following type were operated and the apparatus used was shown in Fig. 1.

$$
\mathrm{Zn} / \mathrm{LiCl}-\mathrm{KCl} \text { (eutectic) }+5 \% \mathrm{ZnCl}_{2} / \mathrm{Zn}-\mathrm{Sb}
$$

The sample container consisted of tubes of high alumina content and its walls had a small hole through which electrolyte could pass. After the bath was kept at a costant temperature for several hours in argon atomsphere, the equilibrium e.m.f. was measured at $550 \sim 650^{\circ} \mathrm{C}$. The results obtained are shown in Fig. 2.

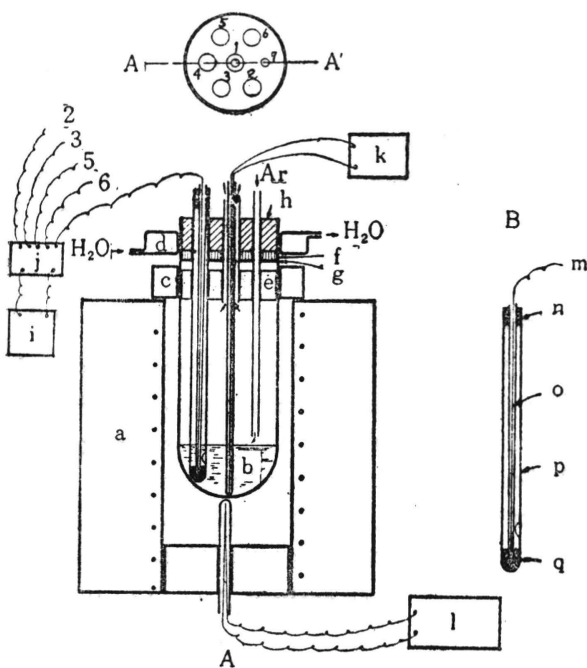

A : A-A' section

B : Sample containing tube

1: Alumel-chromel thermocuple

2: Pure zinc

3 6: Alloy

7 : Pipe for pouring argon gas

a : Heating furnace

b : Electrolyte $\left(\mathrm{LiCl}, \mathrm{KCI}+\mathrm{ZnCl}_{2}\right)$

c: Asbestos

d: Water jacket

e : High alumina block

f: Asbestos plate

g: Stainless steel plate

h : Rubber stopper

i : K-2 type potentiometer

$\mathrm{j}$ : Turnning switch

k: Pyrometer

1: Automatic temperature controller

$\mathrm{m}$ : Tungusten wire

n : Rubber stopper

$o:$ Terex glass pipe

$\mathrm{p}$ : High alumina tube

$q$ : Pure zinc or alloy

Fig. 1 Experimental apparatus

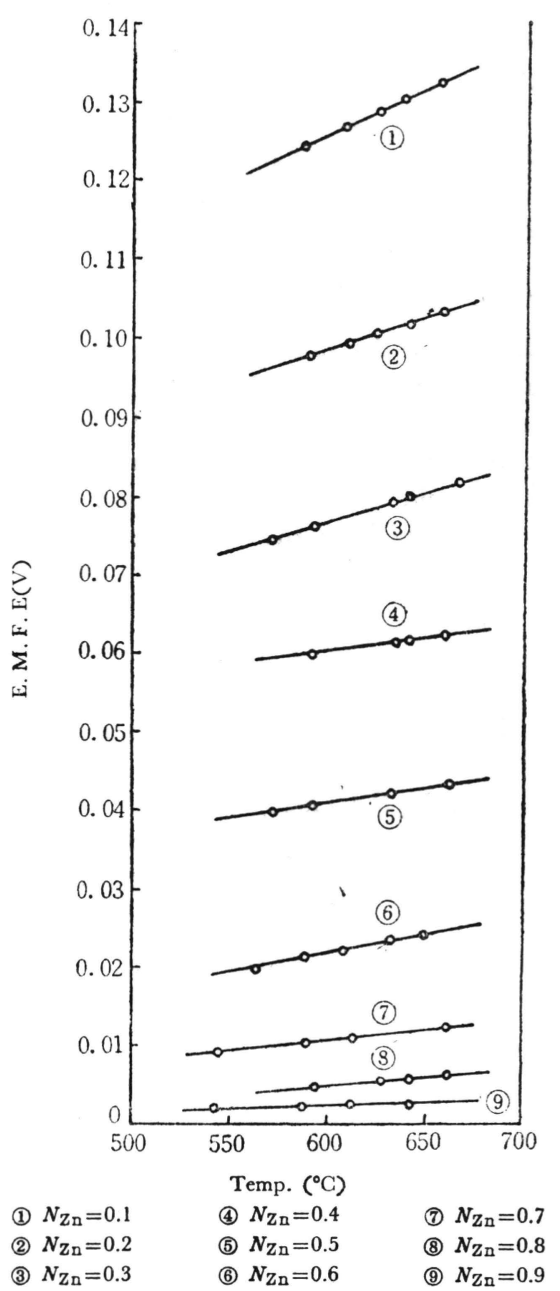

Fig. 2 Electromotive force for $\mathrm{Zn}-\mathrm{Sb}$ binary alloy solution 
The activity of zinc was calculated according to equation (1) from these results, and the activity of antimony was also calculated according to the Gibbs-Duhem equation.

$$
\log a_{\mathrm{Zn}}=-2 \mathrm{EF} / 4.574 \mathrm{~T}
$$

The results calculated at $600^{\circ} \mathrm{C}$ are shown in Fig. 3. With use of the equations (2), (3) and (4), partial molal free energy, entropy and heat of mixing were calculated. And these integral values were determined according to equation (5).

$$
\begin{aligned}
& \Delta \bar{F}_{\mathrm{Zn}}=R T \ln a_{\mathrm{Zn}}=4.574 \mathrm{~T} \log a_{\mathrm{Zn}}=-2 \mathrm{EF} \\
& \Delta \bar{S}_{\mathrm{Zn}}=2 F(\partial E / \partial T) \\
& \Delta \bar{H}_{\mathrm{Zn}}=-2 F[E-T(\partial E / \partial T)]=\Delta \bar{F}_{\mathrm{Zn}}+T \Delta \bar{S}_{\mathrm{Zn}} \\
& \Delta F(\Delta H, \Delta S)=N_{\mathrm{Sb}} \int_{1}^{N_{\mathrm{Zn}}} \Delta \bar{F}_{\mathrm{Zn}}\left(\Delta \bar{H}_{\mathrm{Zn}}, \Delta \bar{S}_{\mathrm{Zn}}\right) /\left(1-N_{\mathrm{Zn}}\right)^{2} d N_{\mathrm{Zn}}
\end{aligned}
$$

Figs. 4. 5 and 6 represent excess free energy, heat of mixing and excess entropy of the solution, to compare the property of the solution with that of ideal and regulr solutions.

As shown in Fig. 3, it is observed that the activity of antimony has a negative deviation from Rault's law at all compositions, but that of zinc has a positive or negative deviation in accordance with the mole fraction of zinc being more or less than 0.64. The excess entropy has maximum values at two different

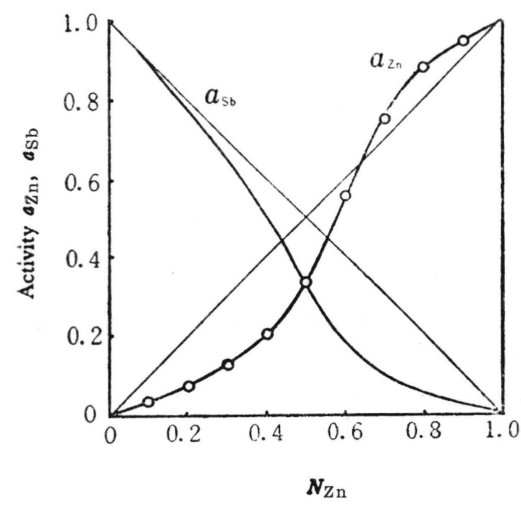

Fig. 3 Activities of Zinc and antimony in $\mathrm{Zn}-\mathrm{Sb}$ binary alloy solution $\left(600^{\circ} \mathrm{C}\right)$

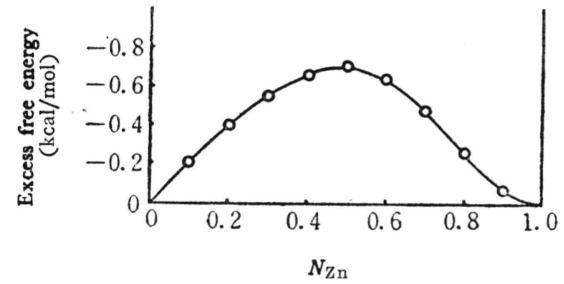

Fig. 4 Excess free energy for $\mathrm{Zn}$-Sn binary alloy solution $\left(600^{\circ} \mathrm{C}\right)$

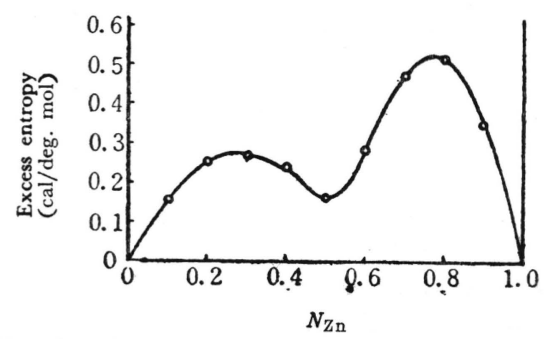

Eig. 5 Excess entropy for $\mathrm{Zn}-\mathrm{Sb}$ binary alloy solution $\left(600^{\circ} \mathrm{C}\right)$

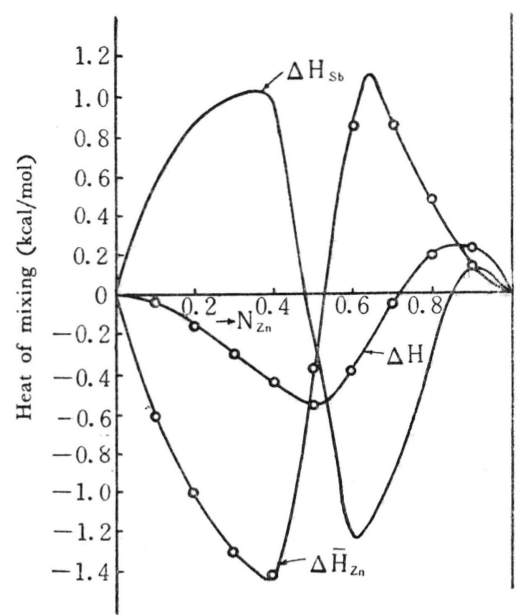

Fig. 6 Heat of mixing for $\mathrm{Zn}-\mathrm{Sb}$ binary alloy solution $\left(600^{\circ} \mathrm{C}\right)$

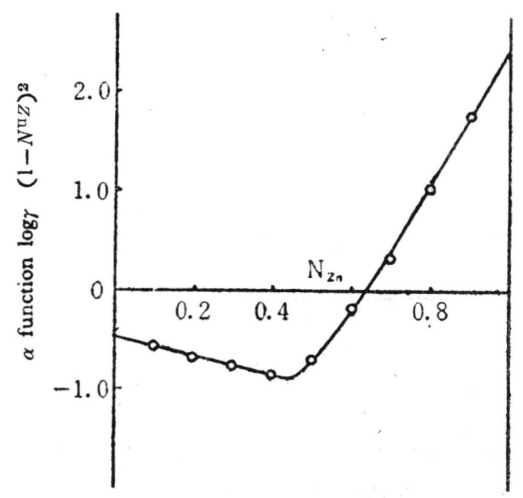

Fig. 7 Function $\log \gamma_{\mathrm{Zn}} /\left(1-N_{\mathrm{Zn}}\right)^{2}$ for $\mathrm{Zn}-\mathrm{Sb}$ binary alloy solution $\left(600^{\circ} \mathrm{C}\right)$ 
compositions as shown in Fig. 5.

Fig. 6. shows the heat of mixing. From these results the solution has a positive or negative heat of mixing in accordance with its zinc content.

Peculiarity of this solution can be shown most distinctly by means of function $\log _{\gamma_{\mathrm{Zn}}} /\left(1-N_{\mathrm{Zn}}\right)^{2}$ which consists of two straight lines with intersect at $N_{\mathrm{Zn}}=0.45$ (Fig. 7).

It was concluded that $\mathrm{Zn}-\mathrm{Sb}$ binary alloy solution has a considerable deviation from ideal and regular solutions and that a drastic change in the behavior of antimony atom occurs at $N_{\mathrm{Zn}}=0.45$.

(Received Nov. 14, 1960)

\title{
Liberature :
}

1) B. J. De Witt, H. Seltz, J. Am. Chem. Soc. 61, 3170 (1939).

\section{Thermodynamic Study of Fused Ternary Alloys by Electromotive Force Measurement (Zn-Cd-Sn System)}

\author{
Zensaku KozuKa, Jyoichiro Morryama and Isao Kushima \\ Dept. of Metallurgy, Faculty of Engineering, Kyoto University, Kyoto
}

In respect to the $\mathrm{Zn}-\mathrm{Cd}-\mathrm{Sn}$ ternary alloy solution, Fiorani ${ }^{1)}$ reported the experimental results and recently $\mathrm{Ptak}^{2)}$ has given a mathematical formula for calculation of the thermodynamic properties.

In this study the properties of $\mathrm{Zn}$-Cd-Sn ternary alloy solution and of three binary alloy solutions composed of these elements at $450 \sim 600^{\circ} \mathrm{C}$ were determined by the electromotive force measurement. The experimental apparatus and technique were similar to those reported in the previous paper, ${ }^{3)}$ but in the case of $\mathrm{Cd}-\mathrm{Sn}$ system pure $\mathrm{Cd}$ was used as a reference electrode and the electrolyte consisted of LiCl-KCl eutectic mixture containing $5 \% \mathrm{CdCl}_{2}$.

The experimental data are shown in Figs. $1 \sim 4$ and Table 1. From these results the excess free energy, $F^{x s}$, excess entropy, $S^{x s}$ and heat of mixing, $\Delta H$, of these binary and ternary alloy solutions at $500^{\circ} \mathrm{C}$ were calculated by the same procedure as reported in the previous paper ${ }^{33,4)}$.

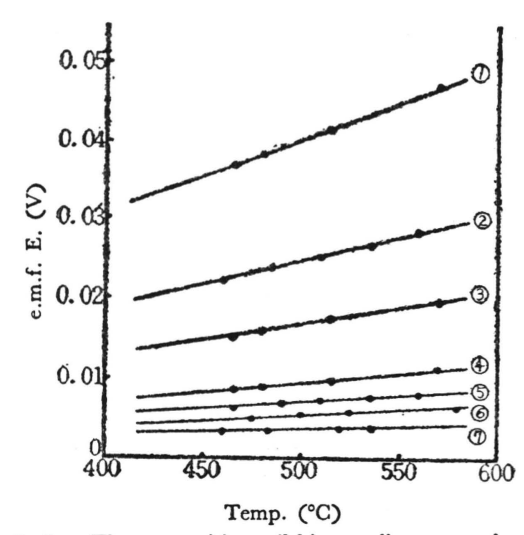

(1)-(7): The compositions of binary alloys were shown in Table 1.

Fig. I The relation between e.m.f. and temperature (Zn-Gd system)

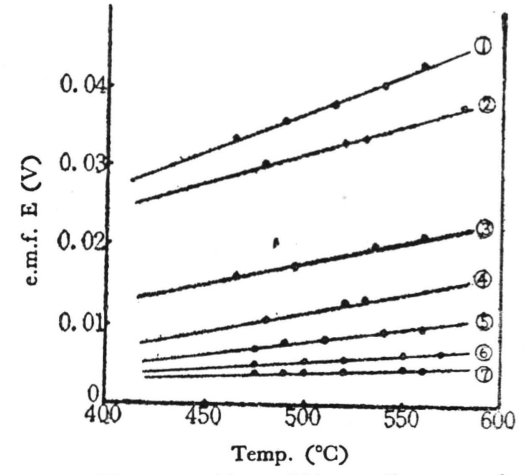

(1)-(7): The compositions of binary alloys were shown in Table 1.

Fig. 2 The relation between e.m. f. and temperature (Zn-Sn system) 